\title{
Conductive Diamond Electrodes for Water Purification
}

\author{
Carlos Alberto Martínez-Huitle*
}

Department of Analytical Chemistry, University of Milan, via Celoria 2, I-20133 Milan, Italy

Received: May 3, 2007; Revised: November 19, 2007

\begin{abstract}
Nowadays, synthetic diamond has been studied for its application in wastewater treatment, electroanalysis, organic synthesis and sensor areas; however, its use in the water disinfection/purification is its most relevant application. The new electrochemistry applications of diamond electrodes open new perspectives for an easy, effective, and chemical free water treatment. This article highlights and summarizes the results of a selection of papers dealing with electrochemical disinfection using synthetic diamond films.
\end{abstract}

Keywords: diamond electrode, water disinfection, water treatment, electrochemical oxidation

\section{Introduction}

Diamond is an extremely hard crystalline form of carbon and it is considered an excellent material for many applications due to its unusual physical and chemical properties. For this reason it has long attracted the attention of scientists and the public. Interest in diamond has been further increased by the discovery of the possibility to produce polycrystalline diamond films with mechanical and electronic properties comparable to natural diamond. Over the last few years, the number of publications has increased considerably regarding the synthesis and/or applications of this new material. Diamond films have been the subject of applications and fundamental research, opening up a new study branch know as diamond science.

\section{Synthesis of Diamond}

As diamond is the densest allotrope of carbon, at high pressure diamond should be the most stable form of solid carbon. This reasoning was the basis for the high-pressure high-temperature (HPHT) growth techniques that have been used in commercial synthesis for the last 30 years. Much effort has been spent during the 60's and 70's to investigate diamond growth at low pressures. Diamond synthesis was successfully achieved by Chemical Vapor Deposition (CVD) techniques at low pressures ${ }^{1}$. Early CVD of diamond was carried out by thermal decomposition of carbon-containing gases such as $\mathrm{CH}_{4}$ and $\mathrm{CO}^{2,3}$ at gas temperatures between 600 and $1200{ }^{\circ} \mathrm{C}$. The typical deposition conditions were: methane concentration of $1 \%$ in hydrogen, substrate temperature of $700-1000{ }^{\circ} \mathrm{C}$, filament temperature approximately of $2000{ }^{\circ} \mathrm{C}$, total gas pressure of $13-133 \mathrm{mbar}$, and reaction time of 3 hours. The diamond growth rates are in the order of 0.1 to near $1000 \mu \mathrm{m} \cdot \mathrm{h}^{-1},{ }^{4}$ demonstrating the good prospect of diamond films for use in some industrial applications. The conductivity of diamond can be improved significantly by doping with boron. Boron doping is usually achieved by adding $\mathrm{B}_{2} \mathrm{H}_{6}, 5,6$ or $\mathrm{B}\left(\mathrm{OCH}_{3}\right)_{3}^{7,8}$ to the gas stream, or placing boron powder near the edges of the substrate prior to insertion into the CVD chamber'. Since the late 70's and early 80's, CVD technique was established as an economical, relatively fast and easy process for producing diamond. The synthesis of diamond has been extensively explained in different reviews and articles ${ }^{10-12}$.

\section{Characterization of Conductive Diamond Films}

\subsection{Microscopy}

The quality of microcrystalline CVD films is conveniently assessed with scanning electron microscopy (SEM), to ensure that the crystallinity is good. For example, in Figure 1, the presence of various types of crystalline morphologies can be seen. Typically, the (111)type grains are darker, which correlates with the previously mentioned tendency of this grain type to incorporate higher levels of boron; the (100)-type grains are lighter. This produces a characteristic pattern of light and dark areas. SEM is also a good technique with which to examine the surface after the deposition of metal particles ${ }^{13-15}$.

\subsection{Raman spectroscopy}

Raman is an essential characterization technique: one of the routine ways in which it is used is to gauge the presence of $\mathrm{sp}^{2}$ carbon, which shows up typically as a very broad peak centered at ca. $1600 \mathrm{~cm}^{-1}$, while diamond itself has a highly characteristic peak, due to the principal phonon mode, at very close to $1332 \mathrm{~cm}^{-1} 16-18$. This peak is extremely intense for highly crystalline diamond. The presence of a high concentration of boron as a dopant leads to an increase in a broad peak at ca. $1200 \mathrm{~cm}^{-1}$. This peak is thought to be due to the presence of either very small crystalline domains of diamond or disordered diamond ${ }^{16}$, either of which could result from the perturbation of the structure by the boron dopant atoms.

\subsection{X ray photoelectron spectroscopy}

The surface termination of the diamond film, whether hydrogen or oxygen, can affect the electrochemical properties greatly ${ }^{19-25}$. This can be determined through the use of X ray photoelectron spectroscopy (XPS). The $\mathrm{O} 1 \mathrm{~s} / \mathrm{C} 1 \mathrm{~s}$ peak area ratio typically reaches a maximum of 0.10 to 0.15 with increased time of oxidizing treatment, for example, electrochemical oxidation. This may correspond approximately to monolayer coverage with oxygen-containing functional groups. It is possible to attain higher $\mathrm{O} / \mathrm{C}$ ratios with oxygen plasma treatment, but this type of aggressive treatment may lead to surface damage (e.g., graphitization), similar to the type of damage observed by 
bombardment with light ions such as $\mathrm{D}^{+}$and $\mathrm{He}^{+19-25}$. XPS is a useful technique for the examination of chemically modified diamond surfaces, particularly if the modifier contains characteristic elements, e.g., N, Si or F.

\section{Electrochemistry of Diamond}

Electrochemical studies of diamond started more than fifteen years ago, when the first paper on diamond electrochemistry was published $^{26}$. After that, diamond synthesis was discovered through Chemical Vapour Deposition techniques at low pressures and excellent diamond growth rates were obtained ${ }^{1-4}$, thus demonstrating the good prospect for using diamond films in some industrial applications. Then, work started in Japan, the United States of America, France, Switzerland and other countries. Over the last few years, the number of publications has increased considerably. Diamond films have been the subject of applications and fundamental research in electrochemistry, opening up a new branch known as the electrochemistry of diamond electrodes.

The boron-doped diamond (BDD) thin films are found to be particularly attractive for some electrochemical uses due to their outstanding properties, which are significantly different from those of other conventional electrodes. The most important properties of this electrode are a large potential window, lower adsorption, corrosion stability in very aggressive media, high efficiency in oxidation processes, very low double-layer capacitance and background current. A total region of around four volts is available within which rather low background currents are recorded ${ }^{10}$. Therefore, diamond film is a suitable material for some industrial applications. The most important uses are classified in three areas: synthesis of chemicals; electro-analysis and destruction of pollutants. However, the main application/research has been made in the electrochemical oxidation of organic pollutants. Later, the versatility of this material was extended to electro-analysis with several purposes among which given emphasis to inorganic species detection ${ }^{10}$ and biosensors ${ }^{27}$.

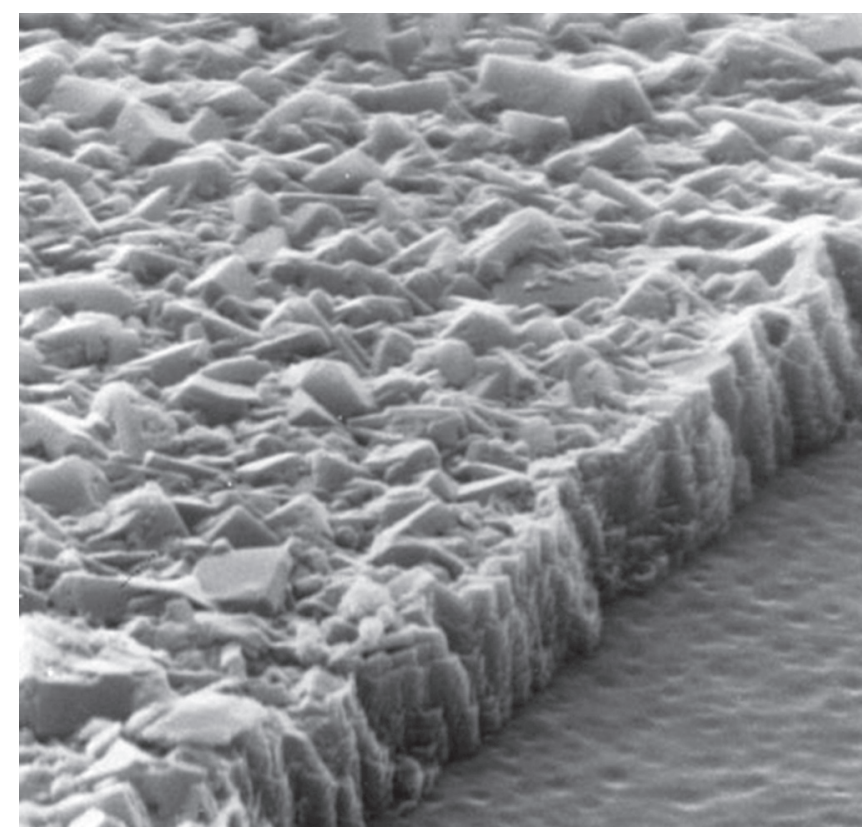

Figure 1. Picture shows diamond crystals synthesized on a silicon substrate by CVD (SEM image reproduced with permission from Adamant Technologies - Switzerland).

\section{Diamond Films for Wastewater Treatment}

The electrochemistry of BDD and its advantages compared to conventional electrodes has been proposed as an electrochemical oxidation method for the destruction and/or the conversion of mixed waste, when the wastewater contains refractory organic pollutants or toxic substances. The principal aim is complete oxidation of organics to $\mathrm{CO}_{2}$ or the conversion of toxic organics to biocompatible compounds ${ }^{28}$. These films represents an efficient anode material for the degradation of refractory or priority pollutants such as ammonia, cyanide, phenol, chlorophenols, aniline, various dyes, surfactants, alcohols and many other compounds ${ }^{28}$. Unlike $\mathrm{PbO}_{2}, \mathrm{SnO}_{2}$ and $\mathrm{TiO}_{2}$, the BDD thin films deposited on $\mathrm{Si}, \mathrm{Ta}, \mathrm{Nb}$ and $\mathrm{W}$ by CVD have shown excellent electrochemical stability ${ }^{8}$. However, the application of BDD electrodes for wastewater treatment has been mostly studied with Si-supported devices (Figure 2), in spite of the difficulties related to their industrial application, due to the fragility and the relatively low conductivity of the Si substrate ${ }^{28}$.

On the other hand, BDD films synthesized on $\mathrm{Nb}$, Ta and $\mathrm{W}$ are promising, but their large-scale utilization is impossible due to the unacceptably high costs of these metal substrates. Therefore, the application of diamond films as a method for the industrial wastewater treatment seems be to long time until a high-quality support for industrial scale to be obtained. The possible alternative is titanium, this material possesses all required features to be a good substrate material and Ti/BDD anode has been also used for the destruction of some pollutants. Nevertheless, Ti use as support for diamond deposition must be studied more extensively. It is still not satisfactory, because cracks may appear and cause the detachment of the diamond film during long-term electrolysis. For these reasons, scientists have currently extended the application of BDD electrodes to water disinfection or purification, where anode dimensions are minor respect to the wastewater treatment plant.

\section{Disinfection/Purification Water}

The contamination of any type of water with micro-organisms constitutes a major sanitary concern. Current technologies for water disinfection are chemical treatment with disinfectants or physical treatments, like radiation, UV-treatment, treatment with oxidants and membrane filtration. Any of them have at least one of the following characteristics: high cost, expensive maintenance, instantaneous treat-

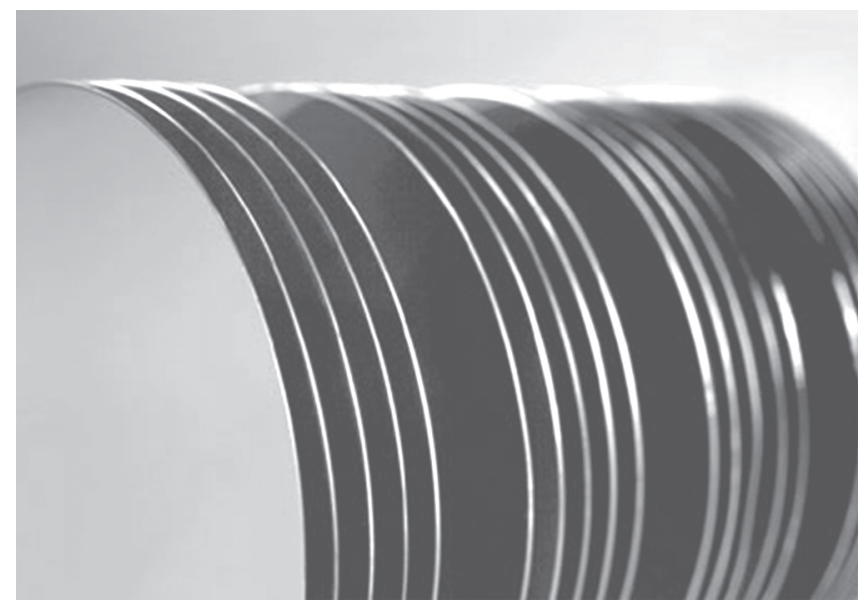

Figure 2. Picture shows diamond electrodes on a silicon substrate by CVD (Reproduced with permission from of Centre Suisse d'Electronique et de Microtechnique, Neuchậtel, Switzerland). 
ment, handling of chemical products. Drinking water disinfection has given a major contribution to the reduction of world mortality during the last century. It has been very helpful in limiting dangerous diseases such as cholera and typhoid. It occurs through multi barrier water treatment processes of settlement, coagulation, filtration or chemical treatment processes, such ozonation and chlorination. Disinfection processes have two main purposes: a primary disinfection (removal or inactivation of microbiological contaminants in the raw water supply) and the provision of a residual disinfection in the distribution network. Therefore, chlorine is the most used chemical method of disinfection, providing both primary and residual disinfection.

The new alternatives are wide-ranging, including several chemical systems; but in recent years, electrochemical disinfection has emerged as one of the most promising alternatives to the conventional purification of water. Electrochemical methods for generating oxidants for disinfection are still under investigation, but the direct and highly efficient electrochemical in situ production of the most common chemical chlorine-based disinfection agents at the BDD surface may achieve more accurate dosages and simplify the handling of chemicals ${ }^{29}$. The electrochemical production of oxidants at the diamond surface can also be exploited for the purification of drinking water and removal of color and odor to prevent waterborne diseases.

Based on the literature, several groups have reported different experimental results using diamond electrode for purification/disinfection water, under different conditions ${ }^{29-46}$. However, the most relevant publications were taken into consideration here for illustrating the advances of this kind of electrochemical application.

Diamond cells ${ }^{29}$ have been used to disinfect potable water contaminated with Legionella $\left(10^{4}-10^{6} \mathrm{Cfu} \cdot \mathrm{mL}^{-1}\right)$. A remarkable inactivation is soon observed after a short time. A low level of disinfectant $(<1 \mathrm{ppm})$ is sufficient to rapidly sanitize a distribution system. Then, a continuous low level of disinfectant (0.1-0.2 ppm) can keep this system purified. The inactivation of Escherichia coli in tap water is at least 3 times faster with electrochemical treatment than with conventional chlorine dosing ${ }^{29}$. A total inactivation of Legionella $(>90 \%)$ can be obtained through the diamond cells if the tap water is electrolyzed at more than $150 \mathrm{~mA} \cdot \mathrm{cm}^{-2}$ and the contact time is sufficiently long $(>1$ hour), as can be seen in Figure 3. Bicarbonates definitely have many advantages, as there is no hypochlorite production (no chlorine drawbacks) and a small total oxidant production for a good inactivation is sufficient, even at small current densities. Since bicarbonates are always present in tap water, electrolysis of tap water can also result in a good Legionella inactivation. The more chloride is contained in the electrolyzed water, the more rapid is the inactivation, even at low current densities, i.e., Legionella can be completely inactivated through the diamond cell with current densities as small as $50 \mathrm{~mA} . \mathrm{cm}^{-2}$ with contact times of 1 minute when $\mathrm{NaCl}$ is added up to approximately $80 \mathrm{ppm} \mathrm{Cl}^{-}$. Whereas, water electrolyzed containing only sulfates has not impact on Legionella inactivation ${ }^{29}$ (Figure 4).

On the other hand, Tröster et al. ${ }^{38}$ have reported important results when diamond electrodes were compared with common electrode materials like $\mathrm{Pt}$ and $\mathrm{IrO}_{2}$ in a bacteria and sugar containing solution (see Figure 5 ) $^{38}$. Treatment with diamond electrodes did not only achieve considerable reduction in bacteria population but also a simultaneous removal of the chemical oxygen demand (COD) by combustion of the sugar. Both effects can be due to the formation of strong oxidant species like hydroxyl radicals. Therefore, this kind of treatment offers the improvement of disinfection methods based on, for instance, oxygen containing species.

Other applications of these diamond films can be for drinking water conditioning, water circuits and process water in industries and energy supply, humidifiers in air-conditioning systems, cooling towers (elimination of algae, Legionella and germs), warm water

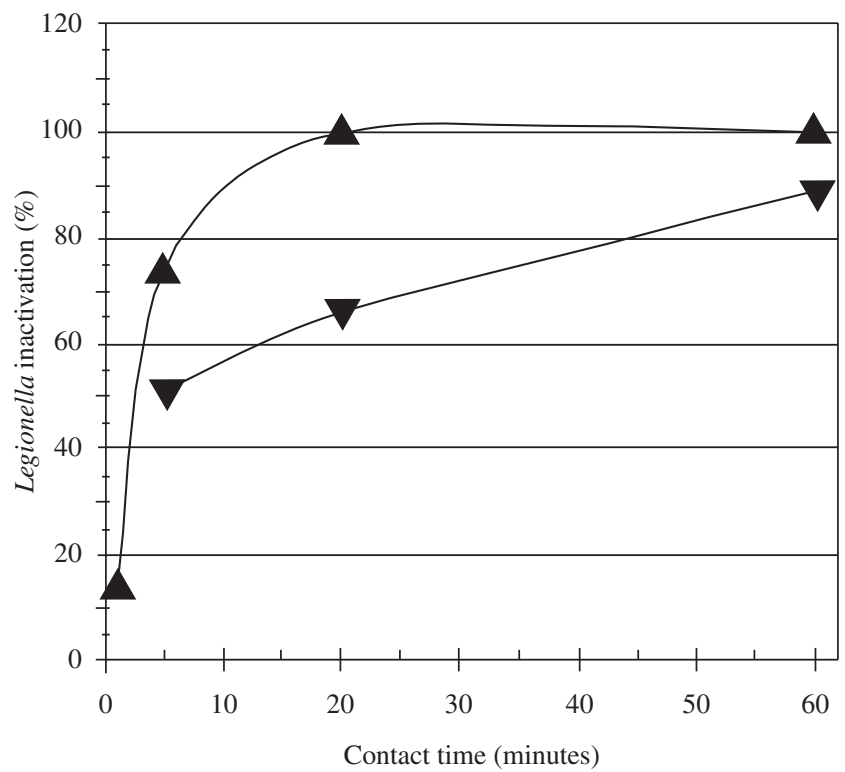

Figure 3. Legionella inactivation with $\mathrm{NaOCl}$ and electrolyzed tap water; ( $\Delta$ ) 0.18 ppm oxidant as $\mathrm{Cl}_{2}(\operatorname{tap}+\mathrm{NaOCl})$ and $(\boldsymbol{\nabla}) 0.19 \mathrm{ppm}$ oxidant as $\mathrm{Cl}_{2}\left(\text { tap- } 150 \mathrm{~mA} \cdot \mathrm{cm}^{-2}\right)^{29}$.

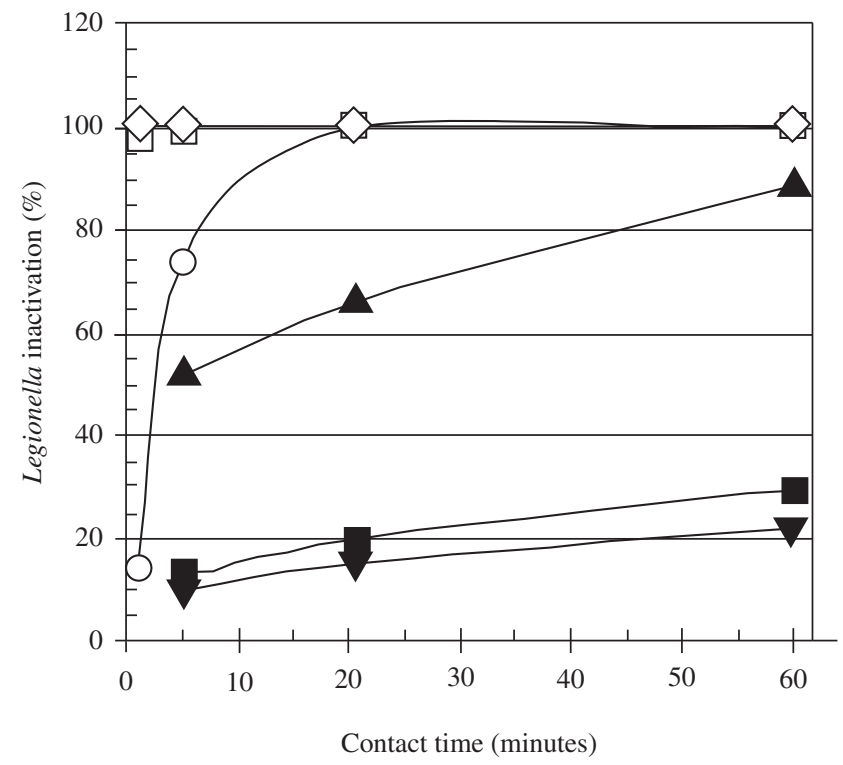

Figure 4. Legionella inactivation vs. contact time after injection, oxidant concentration immediately after Legionella injection and type of water; $(\diamond)$ 0.71 ppm oxidant as $\mathrm{Cl}_{2}\left(\operatorname{tap}+\mathrm{NaCl}-50 \mathrm{~mA} \cdot \mathrm{cm}^{-2}\right)$, (口) $0.67 \mathrm{ppm}$ oxidant as $\mathrm{Cl}_{2}(\operatorname{tap}+\mathrm{NaOCl})$, (०) 0.18 ppm oxidant as $\mathrm{Cl}_{2}(\operatorname{tap}+\mathrm{NaOCl}),(\boldsymbol{\Delta}) 0.19 \mathrm{ppm}$ oxidant as $\mathrm{Cl}_{2}\left(\operatorname{tap}-150 \mathrm{~mA} \cdot \mathrm{cm}^{-2}\right)$, (匹) 0.13 ppm oxidant as $\mathrm{Cl}_{2}$ (tap$\left.100 \mathrm{~mA} \cdot \mathrm{cm}^{-2}\right)$ and $(\boldsymbol{\nabla}) 0.11 \mathrm{ppm}$ oxidant as $\mathrm{Cl}_{2}\left(\operatorname{tap}-50 \mathrm{~mA} \cdot \mathrm{cm}^{-2}\right)^{29}$.

systems in hotels and hospitals (Legionella elimination), disinfection of biologically cleaned wastewater (sewage), ballast water treatment and medical technologies. In addition, electrochemical processes using diamond electrodes have also been applied for the disinfection of chloride-containing swimming pool water ${ }^{38}$. The diamond based systems exhibit a continuous chlorine productivity and higher disinfection performance against bacteria in comparison to directly added hypochlorite $(\mathrm{NaOCl})$. This effect is also based on the production of additional oxidizing species such as hydrogen peroxide in natural mineralized water. 


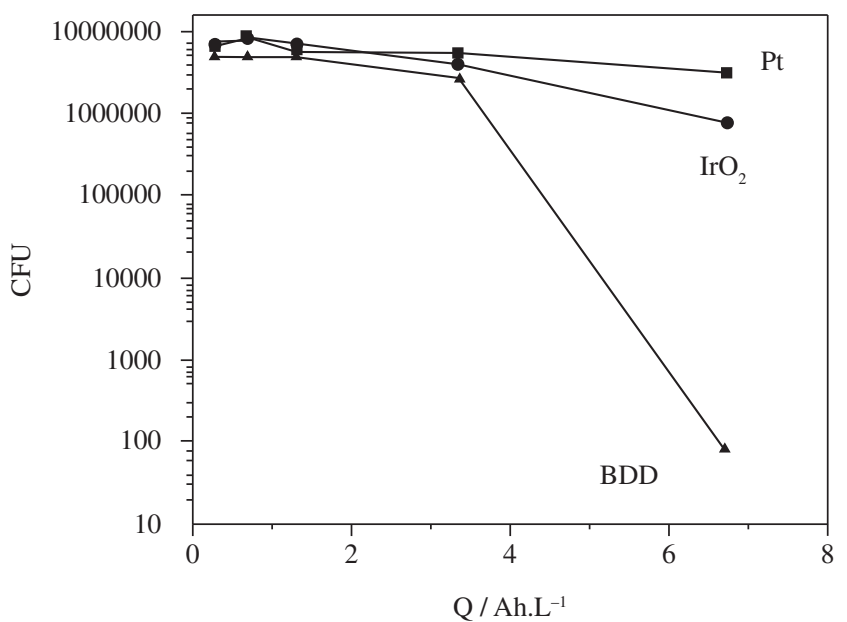

Figure 5. Disinfective performance of diamond electrodes in comparison to common electrode materials: sterilization of a bacteria $\left(14 \times 10^{7} \mathrm{CFU}=\right.$ colony forming units of $E$. coli) and sugar (glucose COD $9 \mathrm{~g} \mathrm{O}_{2} / \mathrm{L}$ ) containing solution ${ }^{38}$.

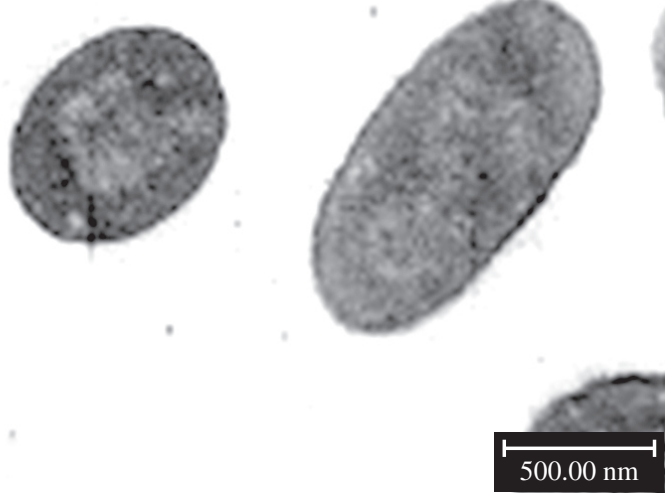

(a)

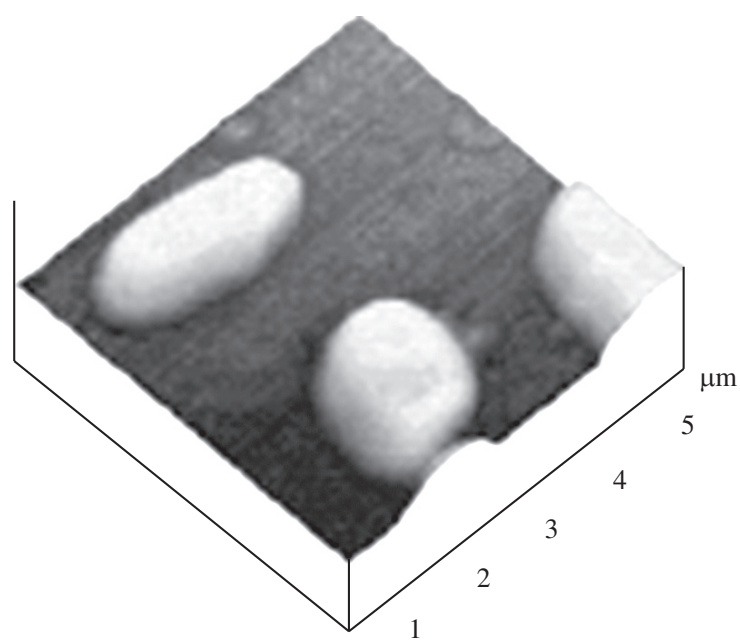

(c)
An example of analogous commercially available technology is the production of anolytes (hydroperoxide and chlorine-oxygen compounds), obtained through the electrochemical treatment of more or less diluted brine solutions ${ }^{39}$. Different systems are already present on the market, having anolyte production capacities from 10 to $5000 \mathrm{~L}$ per hour and low power consumption. This technology is based on modular cells, which can be hydraulically connected in order to obtain monopolar or bipolar electrolyser designs; each module may treat from 10 to $80 \mathrm{~L} \cdot \mathrm{h}^{-1}$ of water, in some seconds. Nevertheless, these cells have constantly used the traditional anodes (such as $\mathrm{Pt}$ and $\mathrm{RuO}_{2}$ ) except diamond; accordingly these traditional anodes only exhibit high disinfection effectiveness when the solution contains chloride ions.

Despite the effectiveness of chlorine as a method of water disinfection, disadvantages like unfavorable taste and odor, its ineffectiveness when used alone against some resistant microorganisms, and the generation of products potentially toxic such as chloroform (the most common chemical by-product of water disinfection, considered harmful for its cancer risks $)^{40}$, were the main reasons for searching alternative disinfection methods. Therefore, new electrochemical

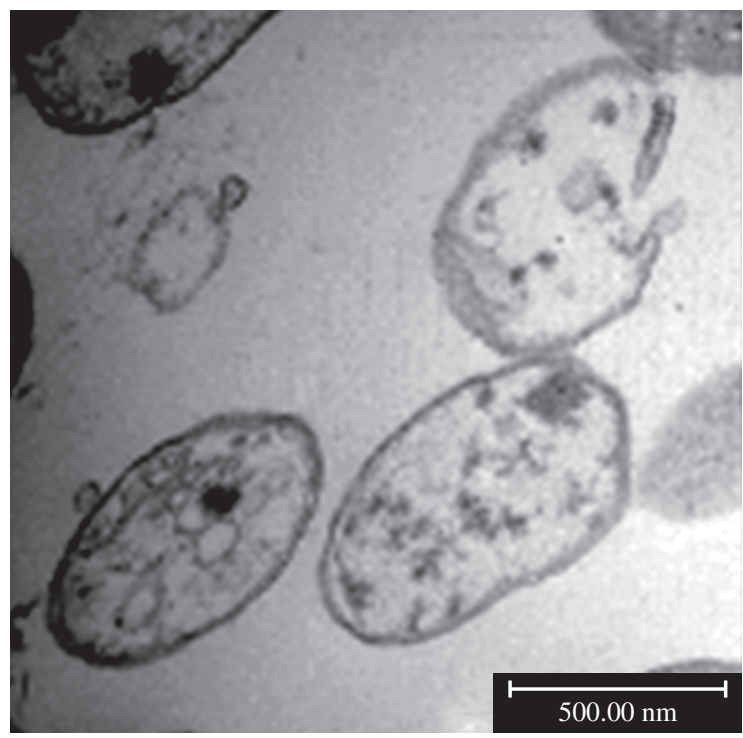

(b)

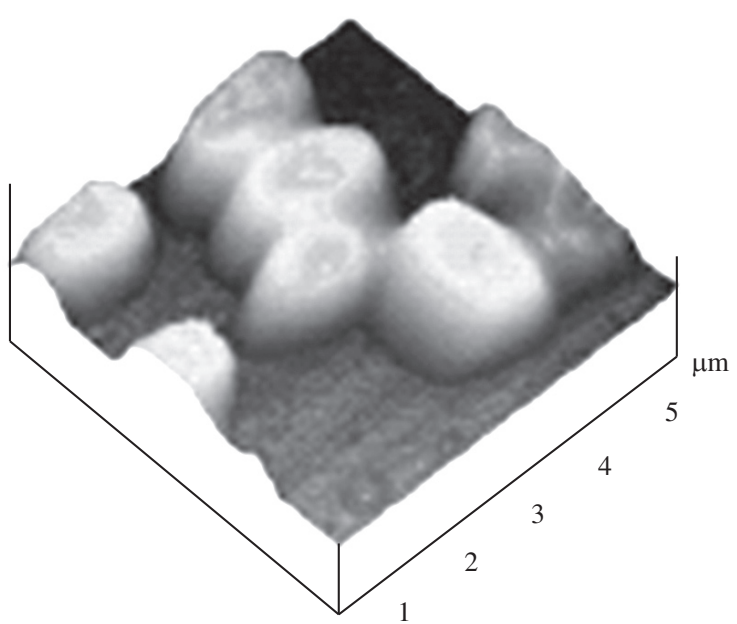

(d)

Figure 6. Morphological change of E. coli cells resulting from the electrolysis at $100 \mathrm{~mA} \cdot \mathrm{cm}^{-2}$ for 5 minutes; $[\text { E. coli }]_{0}=10^{8} \mathrm{CFU}_{\mathrm{mL}}^{-1},\left[\mathrm{KH}_{2}-\mathrm{PO}\right]_{0}=0.2 \mathrm{M}$, $\mathrm{pH}=7.1,25^{\circ} \mathrm{C}$. a) before electrolysis (TEM); b) after electrolysis (TEM); c) before electrolysis (AFM); and d) after electrolysis (AFM) ${ }^{43}$. 
methods are developed to establish chlorine-free systems, oxygenbased disinfection, avoiding the drawbacks of chlorine and the generation of harmful by-products.

In consequence, new evidences for disinfecting water have been reported by Polcaro ${ }^{41,42}$ and Yoon ${ }^{43}$ where no chlorides were added to the aqueous solutions and good performances were obtained using diamond electrodes. Polcaro et al. performed several experiments at diamond films using bacterial suspensions with Escherichia coli, Enterococchi and Faecal coliforms and during the direct oxidation process were achieved results about of $98 \%$ of disinfection ${ }^{41,42}$. The results indicate that the reduction of microorganism populations from $1 \times 10^{3}$ CFU.mL ${ }^{-1}$ to the detection limit is achieved in 60,100 and 300 seconds for E. coli, coliforms and enterococci, respectively. The goodness of these results is evident when compared with other similar electrochemical processes described in the literature. For example, Drees et al ${ }^{44}$ reported that the population of E. coli falls beneath the detection limit in 5 minutes when $10 \mathrm{~mL}$ aliquot of suspension, with initial concentration of $1 \times 10^{3}$ CFU.mL ${ }^{-1}$, was exposed to a current of $5 \mathrm{~mA}$. Patermarakis and Fountoukidis ${ }^{45}$ exposed total coliforms at population density of $200-26,800$ cell. $\mathrm{mL}^{-1}$ in natural surface water to $2.5 \mathrm{~mA} \cdot \mathrm{cm}^{-2}$ and they reduced the culturable counts by an order of magnitude in 15.7 minutes. Matsunaga et al. ${ }^{46}$ reduced $E$. coli from a population density of $1 \times 10^{2}$ cell.mL $\mathrm{mL}^{-1}$ in water to less than $2 \%$ of the initial number with a 10 minutes exposure to $0.7 \mathrm{~V}$. The good efficiency of the direct electrochemical disinfection achieved at BDD anode in diluted $\mathrm{Na}_{2} \mathrm{SO}_{4}$ solutions indicates the important role of the anode material ${ }^{42}$.

Moreover, new evidences of the role of oxygen species in the electrochemical disinfection using boron-doped diamond electrodes in a chlorine-free media were reported by Yoon ${ }^{43}$; thus avoiding any confusion caused by the generation of chlorine and by-products. This research may not seem particularly original, but its result may dramatically modify the scenery in this area because it is a detailed study about the morphological change of the E. coli cells during the electrolysis in an electrochemical free-chlorine system. The morphological changes of the $E$. coli cells were performed by transmission electron microscopy (TEM) and atomic force microscopy (AFM) ${ }^{43}$. Figure 6 shows the TEM images of the untreated and treated E. coli cells. In the untreated $E$. coli cells, the cell walls of both the outer and inner membranes were intact (a). However, after 5 minutes of electrolysis, the drastic changes in the nature of the contents of cell, as well as in the structure of the cell walls, were observed (b). The cell walls appear to be no longer uniform and to have become torn in places, and the cells are mostly empty. This may be one of the typical appearances in the cells damaged by strong oxidants. AFM images (Figure $6 \mathrm{c}$ and $\mathrm{d}$ which show the cells before and after electrolysis) reported by the authors showed, the surface of the untreated cells appears to be smooth and flat, whereas the treated cells have a rough and sunken surface, as if they had shrunk when the inner contents escaped from the cells. These morphological changes can be interpreted by the attack of oxygen species involving hydroxyl radicals ${ }^{28}$ disrupting the integrity of the cell membrane, leading to the lyses of the cells. This study clearly shows that strong oxidant species formation by electrolyzing water can cause a significant inactivation of microorganism, as much as chlorine in the electrochemical disinfection. Furthermore, the potential role of these strong oxidant species, which have oxidizing potentials higher than that of chlorine, deserves to be underlined in treating the spore forming microorganisms that are difficult to inactivate using only chlorine. Therefore, the development of new chemical approaches to disinfecting the water by using diamond films, may lead to an entirely new class of electrochemical "free-chlorine" systems.

\subsection{Perspectives}

Considering the recent advances obtained with diamond electrodes, the results encourage its application in the disinfection water technology, because it reveals higher improvements with respect to other materials. The bacterial decrease and the total oxidation of the organic substances are also important profit determinants, with the adoption of diamond-coated electrodes.

\section{References}

1. Asmussen J, Reinhard DK. Diamond Film Handbook. Michigan State University, East Lansing, MI; 2002. p. 1.

2. Eversole WG. Synthesis of Diamond, US Patents 3,030,187; 3,030,188. 1962.

3. Angus JC, Will HA, Stanko WS. Growth of diamond seed crystals by vapor deposition. Journal of Applied Physics 1968; 39(6):2915-2922.

4. Bachmann PK. In: Lettington A. Steeds JW. (eds.). Microwave plasma CVD and related techniques for low pressure diamond synthesis. Thin Film Diamond, London: Chapman \& Hall; 1994. p. 31.

5. Mort J, Kuhman D, Machonkin M, Morgan M, Jansen F, Okumura K, LeGrice YM, Nemanich RJ. Boron doping of diamond thin films. Applied Physics Letters 1989; 55(11):1121-1123.

6. Fujimori N, Nakahata H, Imai T. Properties of boron-doped epitaxial diamond films. Japan Journal of Applied Physics. 1990; 29(5):824-827.

7. Ran JG, Zheng CQ, Ren J, Hong SM. Properties and texture of borondoped diamond films as thermal sensor. Diamond \& Related Materials. 1993; 2(5-7):793-796.

8. Fryda, M, Herrmann D, Schafer L, Klages C-P, Perret A, Haenni W, Comninellis Ch, Gandini D. Properties of diamond electrodes for wastewater treatment. New Diamond and Frontier Carbon Technol. 1999; 9(3):229-240.

9. Grot SA, Gildenblat GS, Hatfield CW, Wronski CR, Badzian AR, Badzian T, Messier R. The effect of surface treatment on the electrical properties of metal contacts to boron-doped homoepitaxial diamond films. IEEE Electronic Device Letters. 1990; 11(2):100-104.

10. Ferro S. Synthesis of diamond. Journal of Materials Chemistry. 2002; 12(10):2843-2855.

11. Angus JC, Martin HB, Landau U, Evstefeeva YE, Miller B, Vinokur N. Conducting diamond electrodes: applications in electrochemistry. New Diamond and Frontier Carbon Technology. 1999; 9(3):175-187.

12. Fujishima A, Terashima C, Honda K, Sarada BV, Rao TN. Recent progress in electro-analytical applications of diamond electrodes. New Diamond and Frontier Carbon Technology. 2002; 12(2):73-81.

13. Gao J-S, Arunagiri T, Chen J-J, Goodwill P, Chyan O, Perez J, Golden D. Preparation and Characterization of Metal Nanoparticles on a Diamond Surface. Chemistry of Materials. 2000; 12(11):3495-3500.

14. Roy D, Barber ZH, Clyne TW. Ag nanoparticle induced surface enhanced Raman spectroscopy of chemical vapor deposition diamond thin films prepared by hot filament chemical vapor deposition. Journal of Applied Physics. 2002; 91(9):6085-6088.

15. Wang J, Swain GM. Dimensionally stable Pt/diamond composite electrodes in concentrated $\mathrm{H}_{3} \mathrm{PO}_{4}$ at high temperature. Electrochemical Solid-State Letters. 2002; 5(2):E4-E7.

16. Zaitsev AM. In: Prelas MA, Popovici G, Bigelow LK. (edited). Handbook of Industrial Diamond and Diamond Films. New York: Marcel Dekker; 1998. p. 227.

17. Rutledge KM, Gleason KK. Handbook of Industrial Diamond and Diamond Films. In: Prelas MA, Popovici G, Bigelow LK (edited). New York: Marcel Dekker; 1998. p. 413.

18. Knight DS, White WB. Characterization of diamond films by Raman spectroscopy. Journal Materials Research. 1989; 4(2):385-393.

19. Notsu H, Fukazawa T, Tatsuma T, Tryk DA, Fujishima A. Hydroxyl groups on boron-doped diamond electrodes and their modification with a silane coupling agent. Electrochemical Solid State Letters. 2001; 4(3):H1-H3. 
20. Notsu H, Yagi I, Tatsuma T, Tryk DA, Fujishima A. Surface carbonyl groups on oxidized diamond electrodes. Journal of Electroanalytical Chemistry. 2000; 492(1):31-37.

21. Notsu H, Yagi I, Tatsuma T, Tryk DA, Fujishima A. Introduction of oxygen-containing functional groups onto diamond electrode surfaces by oxygen plasma and anodic polarization. Electrochemical Solid-State Letters. 1999; 2(10):522-524.

22. Kondo T, Honda K, Tryk DA, Fujishima A. AC impedance studies of anodically treated polycrystalline and homoepitaxial boron-doped diamond electrodes. Electrochimica Acta. 2003; 48(19):2739-2748.

23. Popa E, Kubota Y, Tryk DA, Fujishima A. Selective voltammetric and amperometric detection of uric acid with oxidized diamond film electrodes. Analytical Chemistry. 2000; 72(7):1724-1727.

24. Popa E, Notsu H, Miwa T, Tryk DA, Fujishima A. Selective electrochemical detection of dopamine in the presence of ascorbic acid at anodized diamond thin film electrodes. Electrochemical Solid State Letters. 1999; 2(1):49-51.

25. Yagi I, Tsunozaki K, Tryk DA, Fujishima A. Control of the dynamics of photogenerated carriers at the boron-doped diamond/electrolyte interface by variation of the surface termination. Electrochemical Solid-State Letters. 1999; 2(9):457-460.

26. Pleskov YV, Sakharova AY, Krotova MD, Builov LL, Spitsyn BV. Photoelectrochemical properties of semiconductor diamond. Journal of Electroanalytical Chemistry. 1987; 228(1-2):19-27.

27. Carlisle JA. Diamond biosensors. Nature Materials. 2004; 3(10):668-669.

28. Martinez-Huitle CA, Ferro S. Electrochemical oxidation of organic pollutants for the wastewater treatment: direct and indirect processes. Chemical Society Reviews. 2006; 35(12):1324-1340.

29. Furuta T, Tanaka H, Nishiki Y, Pupunat L, Haenni W, Rychen Ph. Legionella inactivation with diamond electrodes. Diamond \& Related Materials. 2004; 13(11-12):2016-2019.

30. Horn J, Stepan A. Method for cleaning, sterilizing and disinfecting dishes and other kitchen utensils and cleaning device for such processes. European Patent PCT WO 2006117201; 2006.

31. Matthee T, Fryda M, Mulcahy S, Stalizus W, Nyman L. Emerging technology: Examining the use of diamond electrodes for water treatment. Ultrapure Water. 2006; 23(2):53-56.

32. Fryda M, Matthee T, Mulcahy S, Hampel A, Schafer L, Troster I. Fabrication and application of Diachem electrodes. Diamond \& Related Materials. 2003; 12(10):1950-1956.
33. Rychen P, Haenni W, Pupunat L. Water treatment without chemistry. Chimia. 2003; 57(10):655-658.

34. Bergmann H, Iourtchouk T, Schöps K. Aspects of electrochemical disinfection of drinking water. GDCh-Monographien. 2001; 23 (Elektronenübertragung in Chemie und Biochemie):155-162.

35. Forster H-J, Thiele W, Fassler D, Gunther K. Comparative investigations of hypochlorite formation on platinum and diamond electrodes. New Diamiamond and Frontier Carbon Technology. 2002; 12(2):99-105.

36. Haenni W, Gobet J, Perret A, Pupunat L, Rychen P, Comninellis C, Correa B. Loop-controlled production of chlorine for disinfection of pool water using boron-doped diamond electrodes. New Diamond and Frontier Carbon Technology. 2002; 12(2):83-88.

37. Kraft A, Stadelmann M, Kirstein W. Use of diamond electrodes for electrolytic water purification and disinfection by anodic oxidation. Galvanotechnik. 2000; 91(2):334-339.

38. Tröster I, Schaefer L, Fryda M, Matthee T. Electrochemical advanced oxidation process using DiaChem electrodes. Water Science and Technology. 2004; 49(4):207-212.

39. Bakhir VM, Panicheva SA, Zadorozhni YG. US Pat., 6843 895; 2005.

40. Kerwick MI, Reddy SM, Chamberlain AHL, Holt DM. Electrochemical disinfection, an environmentally acceptable method of drinking water disinfection? Electrochimica Acta. 2005; 50(25-26):5270-5277.

41. Vacca A, Palmas S, Polcaro AM, Mascia M. Disinfection of water by electrochemical treatment at boron doped diamond anodes. World Congress of Chemical Engineering, 7th, Glasgow, United Kingdom; 2005.

42. Polcaro AM, Vacca A, Mascia M, Palmas S, Pompei R, Laconi S. Characterization of a stirred tank electrochemical cell for water disinfection processes. Electrochimica Acta. 2007; 52(7):2595-2602.

43. Jeong J, Kim JY, Yoon J. The Role of Reactive Oxygen Species in the Electrochemical Inactivation of Microorganisms. Environmental Sciences and Technology. 2006; 40(19):6117-6122.

44. Drees KP, Abbaszadegan M, Maier RM. Comparative electrochemical inactivation of bacteria and bacteriophage. Water Research. 2003; 37(10):2291-2300.

45. Patermarakis G, Fountoukidis E. Disinfection of water by electrochemical treatment. Water Research. 1990; 24(12):1491-1496.

46. Matsunaga T, Nakasono S, Takamuku T, Burgess JG, Nakamura N, Sode K. Disinfection of drinking water by using a novel electrochemical reactor employing carbon-cloth electrodes. Applied Environmental and Microbiology. 1992; 58(2):686-689. 